\title{
Behaviors of Nitrogen Atoms in Irradiated Iron and Iron Alloy Revealed by Internal Friction and Electron Microscopy ${ }^{*}$
}

\author{
By Naohiro IGATA, ${ }^{* *}$ Ryukiti R. HASIGUTI, ${ }^{* *}$ and Satio SETO***
}

\section{Synopsis}

The structure changes of iron and an iron alloy induced by neutron irradiation and annealing were investigated from the atomistic point of view. Three kinds of materials, i.e. high purity iron, pure iron, and an iron nickel alloy, were irradiated in the Belgian reactor BR-2. Experiments on Snoek internal friction peaks and electron microscopy were performed. It is concluded that in slowly cooled iron alloy, in which carbon atoms are rather stably precipitated, nitrogen atoms are trapped by irradiation induced point defects to form complexes, which together with interstitial clusters contribute to the irradiation hardening.

\section{Introduction}

Many researches on the structure changes of iron by irradiation have hitherto been reported by many authors from the atomistic point of view. These researches have been performed, for example, by means of internal friction, ${ }^{1)-3)}$ electrical resistivity, ${ }^{4)}$ and electron microscopy.5)-7) Through these studies it has been found that the solute carbon or nitrogen atoms are trapped by irradiation induced point defects ${ }^{1-4)}$ and the complex defects become the nucleation center of the precipitates.5) Chow et al. ${ }^{81,9)}$ considered that the complex defects of solute carbon atoms and irradiation induced point defects are very important in irradiation hardening. Hinkle et al. ${ }^{10)}$ showed that the temperature range for the release of nitrogen atoms from irradiation induced traps is precisely the same as that for the recovery of the irradiation increased yield stresses.

In this study the experiments were performed on pure iron and an iron-nickel alloy, both of which contain carbon and nitrogen, and they were compared with zone melted high purity iron which contains almost no interstitial impurities. Internal friction measurements and electron microscopy were parallely performed using the same lots of materials.

\section{Experimental Procedure}

1. Materials

Three kinds of materials were used. They were high purity iron, pure iron, and an iron-nickel alloy containing $1 \%$ nickel. High purity iron was zone refined from pure iron of Johnson-Matthey \& Co. Zone refining was performed twice under atmosphere of $\mathrm{Ar}+\mathrm{H}_{2}$. After zone refining the Snoek peak of internal friction was not observed above the back ground internal friction of $10^{-3}$, so that solute nitrogen or carbon atoms are estimated to be less than a few ppm. Oxygen would be eliminated to be a few ppm because of the hydrogen atmosphere. Pure iron was prepared from "Puron" which was made by Westinghouse Co. This contains $70 \mathrm{ppm}$ carbon and 35 ppm nitrogen. Table 1 shows the impurity content of "Puron".

The iron-nickel alloy was melted from "Puron" and pure nickel produced by Johnson-Matthey \& Co. using electron beam melting or high frequency induction furnace.

Specimen sizes were $1 \times 10 \times 100 \mathrm{~mm}^{3}$ for internal friction measurements, $0.5 \times 10 \times 100 \mathrm{~mm}^{3}$ for electron microscopy. The specimens were annealed at $550^{\circ} \mathrm{C}$ for $1 \mathrm{hr}$ in the case of pure iron, and $750^{\circ} \mathrm{C}$ for $1 \mathrm{hr}$ both in the cases of iron-1\% nickel alloy and high purity iron. The furnace cooling was performed after annealing for all the three kinds of materials.

\section{Irradiation}

The rigs for irradiation which were composed of capsuled samples were constructed by Mitsubishi Atomic Power Industry Co. The rigs were sent to Belgium and the irradiation was performed in BR-2 reactor in Belgium. The conditions of irradiation are shown in Table 2. After irradiation the rigs were sent back to the Japan Atomic Energy Research Institute, where the specimens were taken out of the capsules.

\section{Experimental Results}

\section{Internal Friction}

In the case of annealed pure iron and annealed iron-

Table 1. Impurity content of "Puron"

\begin{tabular}{|c|c|c|c|c|c|c|c|}
\hline Elements & $\mathrm{C}$ & $\mathrm{O}$ & $\mathrm{N}$ & $\mathrm{Mn}$ & $\mathrm{Si}$ & $\mathrm{Mg}$ & $\mathrm{Cu}$ \\
\hline$(w t \%)$ & 0.007 & - & 0.0035 & 0.003 & 0.007 & - & - \\
\hline Elements & $\mathrm{Al}$ & Co & $\mathrm{Ni}$ & $\mathrm{Cr}$ & $\mathrm{S}$ & $\begin{array}{l}\text { Other } \\
\text { impurity }\end{array}$ & \\
\hline$(\mathrm{wt} \%)$ & 0.009 & 0.000 & 0.012 & 0.001 & 0.006 & - & \\
\hline
\end{tabular}

* Received August 21, 1969.

** Department of Metallurgy, The University of Tokyo, Bunkyo-ku, Tokyo 113.

*** Graduate Student, Department of Metallurgy, Tokai University, Shibuya-ku, Tokyo 151. 
Table 2. The conditions of irradiation

\begin{tabular}{l|c|c|c}
\hline \multicolumn{1}{c|}{ Materials } & $\begin{array}{c}\text { Irradiation time } \\
(\mathrm{sec})\end{array}$ & $\begin{array}{c}\text { Irradiation temperature } \\
\left({ }^{\circ} \mathrm{C}\right)\end{array}$ & $\begin{array}{c}\text { Fast neutrons }>1 \mathrm{MeV} \\
\left(\mathrm{n} / \mathrm{cm}^{2}\right)\end{array}$ \\
\hline High purity iron & $5.047^{1} 8 \times 10^{5}$ & $75^{\circ} \pm 10^{\circ}$ & $3.6 \times 10^{19}(>1 \mathrm{MeV})$ \\
Pure iron & $1.5912 \times 10^{5}$ & $75^{\circ} \pm 10^{\circ}$ & $1.4 \times 10^{20}$ \\
Iron-1\% nickel & $5.0478 \times 10^{5}$ & $75^{\circ} \pm 10^{\circ}$ & $3.6 \times 10^{19}(>1 \mathrm{MeV})$ \\
\end{tabular}

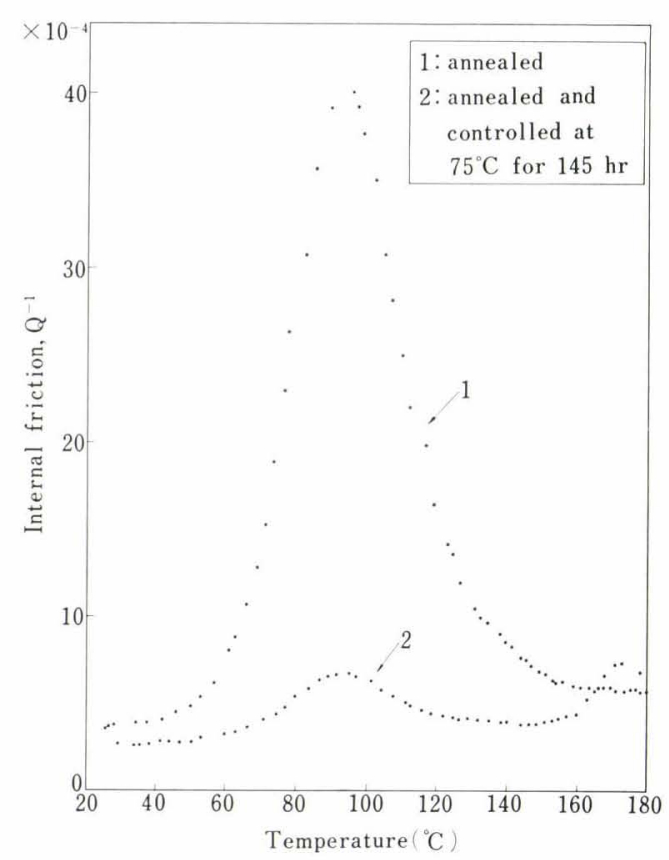

Fig. 1. The nitrogen Snoek peaks in the pure iron before irradiation

$1 \%$ nickel alloy, the Snoek peak heights were $3.5 \times 10^{-3}$ (Fig. 1) and $4.0 \times 10^{-3}$, respectively, which were the nitrogen peaks, as determined from their peak temperatures at the given vibrational frequencies of specimens. This shows that interstitial impurity atoms in solution are mainly nitrogen atoms, although the content of carbon $(70 \mathrm{ppm})$ is larger than that of nitrogen $(35 \mathrm{ppm})$, and that almost all the carbon atoms are precipitated under the given annealing conditions. This would come from the fact that the solubility of nitrogen is far higher than that of carbon at the annealing temperatures in iron or dilute iron alloy.

The Snoek peak height decreases with room temperature aging; for example, after aging of one year and nine months at room temperature the Snoek peak height of pure iron decreased from $3.5 \times 10^{-3}$ to $4.1 \times$ $10^{-4}$. After the control treatment, viz. keeping at $75^{\circ} \mathrm{C}$ for $145 \mathrm{hr}$, the Snoek peak height became $3.3 \times 10^{-4}$ as shown in Fig. 1. These results show that the amount of precipitate of nitrogen is almost equal in aged and controlled specimens.

After irradiation, the Snoek peaks were not observed in both cases of pure iron and iron-1\% nickel alloy, although in the controlled specimen the nitrogen Snoek peak remained observable (Fig. 1). This shows that nitrogen atoms are trapped by irradiation produced defects or are enhanced to precipitate by irradiation. Since the amount of precipitates as
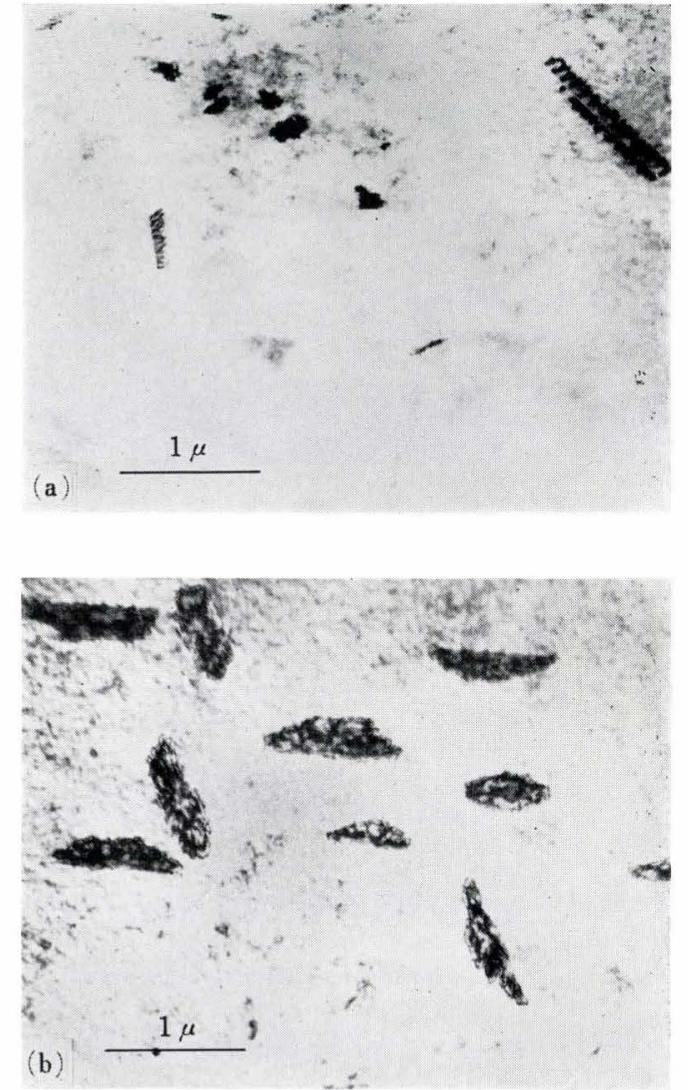

Photo. 1. Metastable precipitates (a) after irradiation and (b) after aging in the iron-nickel alloy

observed by electron microscope is rather smaller after irradiation (Photo. 1(a)) than in controlled specimens (Photo. 1(b)), the above mentioned irradiation effect would be the formation of complexes of nitrogen atoms and radiation produced point defects which can not be observed by electron microscope.

The reappearance of the Snoek peak by post irradiation annealings for $15 \mathrm{~min}$ at various temperatures up to $450^{\circ} \mathrm{C}$ is shown in Fig. 2. These peaks are again nitrogen peaks. This means that the resolution of nitrogen complexes formed by irradiation takes place, while carbon precipitates formed during the initial $550^{\circ}$ or $750^{\circ} \mathrm{C}$ annealing do not resolve by the above annealings up to $450^{\circ} \mathrm{C}$.

For comparison the above results in the form of the Snoek peak heights are plotted in Fig. 3 together with the results of reannealing of unirradiated annealed iron and the results on iron containing $173 \mathrm{ppm}$ nitrogen which were reported by Soeno et al. ${ }^{11)} \mathrm{Al}-$ though the reappearance of the Snoek peak in unirradiated specimens begins at about $200^{\circ} \mathrm{C}$, it begins in irradiated specimens at higher temperatures viz. 


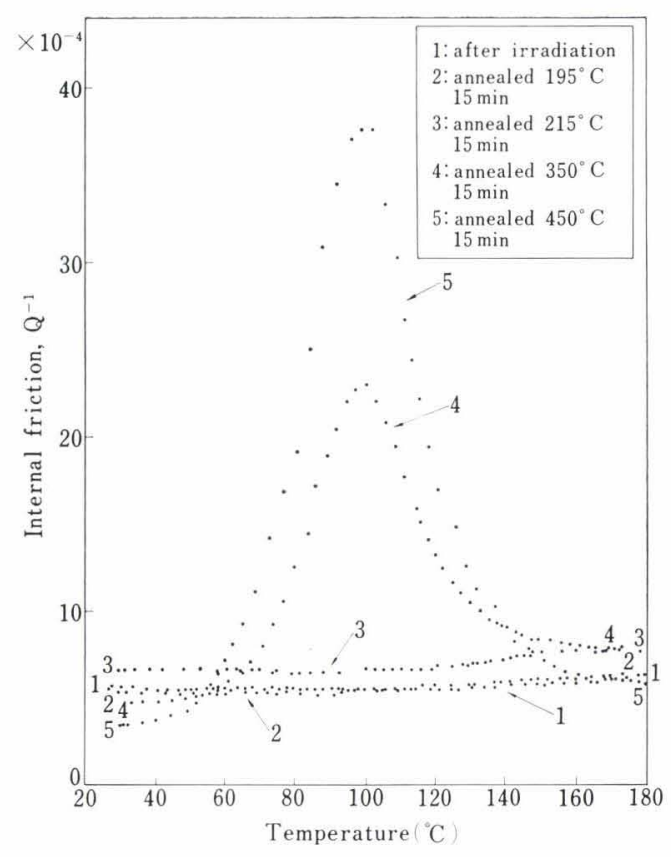

Fig. 2. The changes of the nitrogen Snoek peak in the pure iron after irradiation and after post irradiation annealings

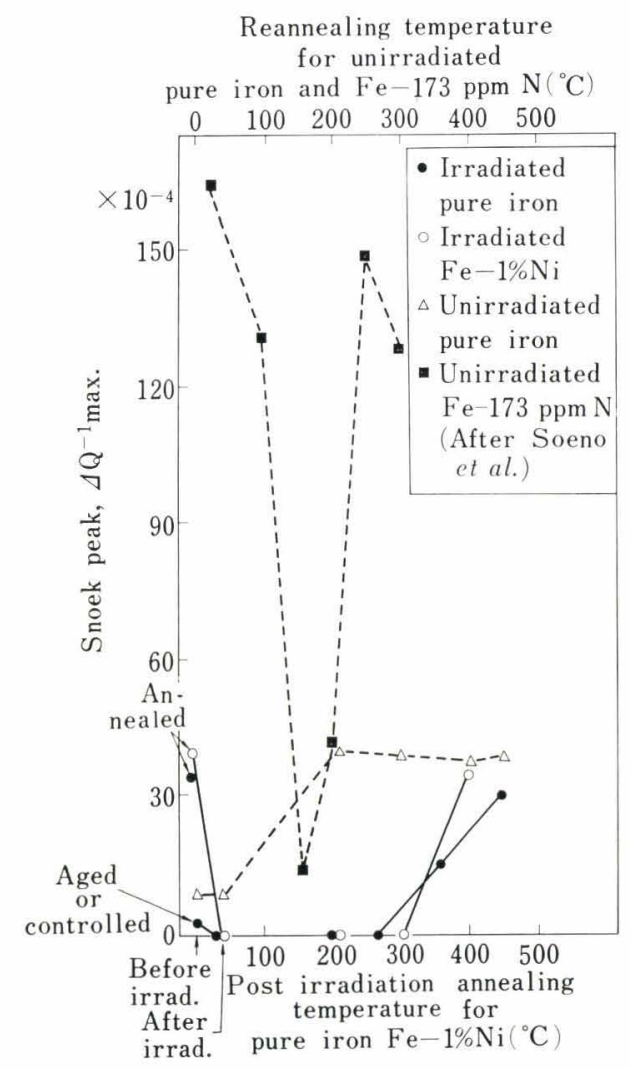

Fig. 3. The change of the nitrogen Snoek peak height due to irradiation or post irradiation annealings compared with the results of unirradiated specimens

above $250^{\circ} \mathrm{C}$ for pure iron and above $300^{\circ} \mathrm{C}$ for ironnickel alloy.

In the case of the annealed high purity iron, the Snoek peak was not observed and the background internal friction was rather high, i.e. $1 \times 10^{-3}$ as shown

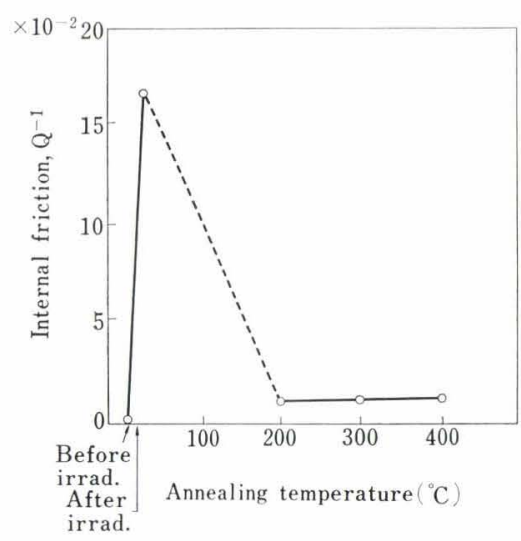

Fig. 4. The change of background damping of the high purity iron due to irradiation and post irradiation annealing

in Fig. 4. After irradiation the background increased to $1.6 \times 10^{-1}$ and by the post irradiation annealing at $200^{\circ} \mathrm{C}$, it decreased to $1.3 \times 10^{-2}$. This background did not recover completely even after annealing at $400^{\circ} \mathrm{G}$ for $15 \mathrm{~min}$. These behaviors are quite different from those of other materials described above, and can not be discussed along the similar line because there appears no Snoek peak.

\section{Transmission Electron Microscopy}

In both cases of pure iron and $\mathrm{Fe}-1 \% \mathrm{Ni}$ the precipitates, which are considered mainly due to nitrogen because of their correspondent behaviors of nitrogen Snoek peaks, become visible in the aged or controlled specimen. In irradiated specimens the precipitates were smaller than in the aged or controlled specimen in both cases of pure iron and $\mathrm{Fe}-1 \% \mathrm{Ni}$. Photographs l(a) and (b) show the case of $\mathrm{Fe}-1 \% \mathrm{Ni}$. These results show that solute nitrogen atoms must be trapped by irradiation induced defects to form complexes which can not be observed by electron microscope as mentioned in the preceding subsection. Dislocation loops were not observed in these specimens.

In post irradiation annealing, the resolution of the precipitates was observed, corresponding to the recovery of the Snoek peak in the case of pure iron and $\mathrm{Fe}-1 \% \mathrm{Ni}$.

In the case of high purity iron, no visible changes were observed.

\section{Discussion and Conclusions}

The behavior of solute interstitial impurity atoms in the irradiated iron is now fairly well understood. From the bahaviors of Snoek internal friction described in Sec. III, it is concluded that in iron, in which carbon atoms are rather stably precipitated, nitrogen atoms in solution are trapped by irradiation induced point defects to form complexes.

According to Eyre and Bartlett ${ }^{12)}$ interstitial clusters are observed by electron microscope in neutron irradiated iron when total dose of neutron is as high as $10^{20}$ nvt. Interstitial clusters are not observed if the neutron dose is as low as $10^{19} \mathrm{nvt}$, but it is believed 
that smaller interstitial clusters which can not be observed by electron microscope do exist at the low dose of $10^{19}$ nvt. Eyre and Bartlett consider that vacancies are trapped by interstitial impurity atoms to form complexes.

It would be evident that in our iron samples interstitial clusters are formed although they are too small to be observed by electron microscope. Then our nitrogen-point defect complexes must be nitrogenvacancy complexes. However, we should consider that $V_{m} \mathcal{N}_{n}$ complexes are not always $V_{1} \mathcal{N}_{1}$, as will be discussed later. Here $m$ and $n$ are the numbers of vacancies and nitrogen atoms, respectively, in a complex.

Now it is considered that both the small interstitial clusters and the $V_{m} \mathcal{N}_{n}$ complexes contribute to the irradiation hardening of our iron specimens, because the annealing temperature of these clusters and complexes nearly corresponds to the recovery temperature of yield strength ${ }^{10), 13)}$ as described below.

By annealing above $250^{\circ} \mathrm{C}$ the $V_{m} \mathcal{N}_{n}$ complexes begin to dissociate and the liberated vacancies annihilate the interstitial clusters. Thus both the $V_{m} \mathcal{N}_{n}$ complexes and the interstitial clusters disappear leaving nitrogen atoms in solution which give rise to the reappearance of nitrogen Snoek peak. This annealing mechanism is evidenced by the fact that the reappearance temperature range of nitrogen Snoek peak (Fig. 3 ) and the disappearance temperature range of interstitial clusters ${ }^{12)}$ are almost the same.

The annealing temperature range spreads from about $250^{\circ} \mathrm{C}$ to about $450^{\circ} \mathrm{C}$ as shown in Fig. 3. This is too wide a range to be considered as due to a single activation process. It should be considered, therefore, that the $m$ and $n$ in $V_{m} \mathcal{N}_{n}$ take several different values including $m=1$ and $n=1$, so that the dissociation energy of $V_{m} \mathcal{N}_{n}$ complexes takes several different values accordingly, which results in a wide annealing range.

It should be pointed out here that the temperature of nitrogen resolution from the $V_{m} \mathcal{N}_{n}$ complexes in irradiated iron, i.e. $250^{\circ}$ to $450^{\circ} \mathrm{C}$ (Fig. 3), is higher than the temperature of nitrogen resolution from the nitrogen metastable precipitates in unirradiated iron, i.e. $150^{\circ}$ to $200^{\circ} \mathrm{C}$ (Fig. 3). This shows that the dissociation energies of the $V_{m} \mathcal{N}_{n}$ complexes are larger than the dissociation energy of the metastable precipitates of nitrogen. In other words the $V_{m} \mathcal{N}_{n}$ complexes have fairly large binding energies. This is also supported by the fact that the metastable precipitates as observed by electron microscope are less in the irradiated iron-1\% nickel than in the unirradiated one (Photos. 1 (a) and (b)), although there remains almost no nitrogen atom in solution in the irradiated iron as shown in Figs. 2 and 3. This is understood if we consider that nitrogen atoms are more strongly bound in the $V_{m} \mathcal{N}_{n}$ complexes than in the metastable precipitates.

Finally, it should be noted here again that the pure iron and the iron-1\% nickel alloy behave very similarly to each other as far as the problems discussed in this paper are concerned, while the high purity iron behaves quite differently from the above two materials.

\section{Acknowledgements}

The authors wish to express their gratitude to the Science and Technology Agency of Japan and to the Iron and Steel Institute of Japan for their financial support to this research, and also to the members of the hot laboratory of the Japan Atomic Energy Research Institute for their cooperation in experiments in the semi-hot cell.

\section{REFERENCES}

1) H. Wagenblast and A. C. Damask: J. Phys. Chem. Solids, 23 (1962), 221.

2) J. E. McLennan and J. E. Hall: J. Austr. Inst. Metals, 8 (1963), 191.

3) J. T. Stanley: Diffusion in Body Centered Cubic Metals, (1965), Chap. 26, pp. 349-556, Amer. Soc. for Metals, Metals Park, Ohio.

4) F. E. Fujita and A. C. Damask: Acta Met., 12 (1964), 331.

5) D. Hull and I. L. Mogford: Phil. Mag., 6 (1961), 535.

6) B. L. Eyre: Phil. Mag., 7 (1962), 2107.

7) J. S. Bryner: Acta Met., 14 (1966), 323.

8) J. G. Y. Chow and S. B. McRickard: Symposium on Flow and Fracture of Metals and Alloy in Nuclear Environments, ASTM STP380, (1965), 120.

9) J. G. Y. Chow, S. B. McRickard, and D. H. Gurinsky: Symposium on Radiation Effects on Metals and Neutron Dosimetry, ASTM STP341, (1963), 46.

10) N. E. Hinkle, S. M. Ohr, and M. S. Wechsler: The Effects of Radiation on Structural Metals, ASTM STP, (1967), referred by M. S. Wechsler in Nuclear Safety Vol. 8, No. 5 (1967), 463.

11) K. Soeno and M. Tsuchiya: J. Japan Inst. Metals, 4 (1967), 305.

12) B. L. Eyre and A. F. Bartlett: Phil. Mag., 12 (1965), 261.

13) R. R. Hasiguti, N. Igata, H. Kaneko, K. Kitajima, S. Koda, G. Mima, and T. Yamane: to be published. 